\title{
Feelings Experienced by Informal Caregivers of Patients with Dementia, from the Moment of Diagnosis Until the Beginning of Psychotherapy
}

\author{
Makri $\mathbf{M}^{1,3 *}$, Sourgouni $E^{2}$, Tsatali $\mathbf{M}^{1}$ and Tsolaki \\ $\mathbf{M}^{1,3}$ \\ ${ }^{1}$ Greek Association of Alzheimer Disease and Related \\ Disorders, Thessaloniki, Greece \\ ${ }^{2}$ Aristotle University of Thessaloniki, Faculty of \\ Philosophy, School of Psychology, Thessaloniki, Greece \\ ${ }^{3}$ Aristotle University of Thessaloniki, Faculty of Medicine, \\ School of Neuroscience, Thessaloniki, Greece \\ *Corresponding author: Makri M, Greek Association \\ of Alzheimer Disease and Related Disorders, 13 P. Sindika \\ Street, Analipsi, Thessaloniki, P.C. 54643, Greece
}

Received: March 10, 2021; Accepted: April 14, 2021; Published: April 21, 2021

\begin{abstract}
When dementia is diagnosed, specific emotions, crucial for the postdiagnostic experience, emerge in the family members of the person with dementia. The present study investigated feelings about the diagnosis at the time of its announcement as well as the feelings that urged family members to get involved in counseling sessions or delay seeking help. Semi-structured interviews were conducted with nine participants recruited from an Alzheimer Association. Three key topics emerged from the analysis: "Experiencing the diagnosis", "Experiencing dementia" and "Understanding psychotherapy". The three topics included five, three, and three specific sub-topics, respectively. Most participants reported having feelings of loss, a sense of helplessness, and feelings of responsibility and trauma that were followed by a period of loneliness. They also reported having developed defenses and having reached their limits. All participants perceived psychotherapy as a means of bringing relief, a sense of sharing, empowerment, and an opportunity for openness.
\end{abstract}

Keywords: Alzheimer's disease; Dementia; Family caregivers; Feelings; Diagnosis; Counseling

\section{Abbreviations}

PwD: People with Dementia; Alzheimer Hellas, DCCSH: Greek Association of Alzheimer's Disease and Related Disorders' Day Care Centre "Saint Helen"

\section{Introduction}

Alzheimer's Disease (AD) is a devastating disease that affects more than 50 million people worldwide. This number is expected to double every 20 years, reaching 75 million in 2030 and more than 150 million in 2050 [1]. The statistics related to AD and its effect on patients, their family, and the entire health-care system are staggering [2]. In 2018, more than 16.1 million caregivers provided an estimated 18.4 billion hours of unpaid care. However, AD costs to caregivers more than just their time. Some family members spend more than $\$ 10,000$ a year caring for the person living with $\mathrm{AD}$, whereas in 2018 $\mathrm{AD}$ and other dementias were estimated to cost approximately $\$ 277$ billion to each nation [3].

It should be noted, however, that the impact of the $\mathrm{AD}$ diagnosis on caregivers is multifaceted. Besides the financial impact onto the entire health-care system [4], the $\mathrm{AD}$ diagnosis puts increasingly more emotional strain on family and caregivers, even from the diagnosis announcement [5]. Specifically, the sense of safety and security is shaken, the sense of continuity is disturbed, whereas the future seems uncertain [6]. According to recent findings, caregivers, at the time of diagnosis, experience sudden changes in their relationships and family structure, whereas they anticipate an uncertain future [7-10]. Moreover, during caregiving, caregivers often report high levels of stress, low self-esteem, low sense of well-being, depressive symptomatology, increased levels of burden, compromised physical health, and, sometimes, premature death is noted [11-13]. In other words, caregivers suffer from many psychological problems as well as changes in social relationships.

Diagnosis is seen as a multidisciplinary process, which also involves the collaboration between physicians, People with Dementia (PwD), and their families. According to an influential report by the Alzheimer's Disease International Organization [14], «national dementia strategies should promote early diagnosis and intervention». It is worth noting that families of PwD need a timely diagnosis, in order patients and their caregivers be able to understand the care plan and comply with the medical guidelines as the disease progresses $[15,16]$. Also, the way in which the diagnosis is announced, as well as the support provided after the diagnosis, can impact on caregivers' adjustment during care $[14,17]$. However, the social stigma related to dementia is often seen as a major obstacle for timely diagnosis and support [18], because general practitioners and the public are not sufficiently informed about dementia.

To conclude, according to Iliffe et al. (2003) [19], clinicians need to be trained how to announce the diagnosis, provide up-to-date guidelines about the post-diagnosis care and support, and provide the caregivers an individualized care plan according to each patient's needs. It is suggested that if provided with adequate support, the feelings of shock, grief, anger, and loss that PwD and families may experience, can be counteracted by feelings of reassurance and empowerment $[14,20]$. On the other hand, the more anxiety and guilt more caregivers feel, the more likely they are to use defensive mechanisms in order to cope with the negative emotions and to seek support [21]. It has also been found that caregivers' reluctance to discuss family issues and health problems is associated with less
J Fam Med - Volume 8 Issue 3 - 2021

ISSN : 2380-0658 | www.austinpublishing group.com

Makri et al. (C) All rights are reserved
Citation: Makri M, Sourgouni E, Tsatali M and Tsolaki M. Feelings Experienced by Informal Caregivers of Patients with Dementia, from the Moment of Diagnosis Until the Beginning of Psychotherapy. J Fam Med. 2021; 8(3): 1248. 
social and emotional support received [21]. Being aware of their concerns, needs, and feelings, caregivers are more willing to seek help in their social network as well as in the social services [3]. Over the last decades, numerous psychosocial interventions, necessary for the caregivers' support, have been developed [22] enhancing self-efficacy, coping, mastery and positive effects on caregivers' wellbeing [23].

Lastly, the circumstances under which the announcement of the diagnosis takes place, as well as the caregivers' first feelings and needs, are an under-developed research area. Some research findings on the post-diagnostic experience of $\mathrm{PwD}$ and their caregivers have revealed that a major issue for both of them is the meaning of post-diagnostic life and the adjustment to loss [24-26].

Our research aimed at providing an in-depth understanding of the first emotions of caregivers of PwD after the diagnosis of $\mathrm{AD}$ and their development until psychotherapy starts. Specifically, we focused, firstly, on the possible stages of the development of caregivers' emotions and analyzed caregivers' cognitive appraisals and experiences, from the time the diagnosis was announced to the beginning of psychotherapy. Secondly, the time passed from the first announcement of diagnosis until the decision to ask psychological support was measured along with the feelings that prompted caregivers to this decision, or made them delay from seeking help. Finally, the present study investigated caregivers' comprehension, beliefs and attitudes about psychotherapy, as well as their expectations from starting psychotherapy.

\section{Methods}

\section{Design}

The study employed a qualitative analysis of interviews with caregivers of PwD. The data were analyzed in accordance with the principles of Interpretative Phenomenological Analysis (IPA). This methodology was chosen because it has been used in the study of caregiving experiences from the participants' personal perspective $[27,28]$. Specific topics reflecting the caregivers' experiences were identified by the researchers and based on previous research. The interviews took place at the beginning of the study. The questions included how caregivers of PwD felt at the time of diagnosis, how their emotions were changing over time, and when they started psychotherapy.

\section{Procedure}

The study took place at the Greek Association of Alzheimer's Disease and Related Disorders' Day Care Centre "Saint Helen" (Alzheimer Hellas, DCCSH) at Thessaloniki. Ethical approval was given by the DCCSH ethics committee. The interviews were carried out between March and May 2017.

Participants had visited the Caregiver Center at the DCCSH, in order to participate in the psychoeducational and psychotherapy interventions which are implemented especially for this population. The researcher was initially given a list of 15 prospective participants, who met the study's eligibility criteria, by the psychologists who were responsible for the implementation of the program. The potential participants were invited to participate in the survey by telephone. Nine of them agreed to participate. The interview meetings took place after psychotherapeutic group sessions and/or an independent day at their convenience. Participation was voluntary and participants were informed about the aims of the study prior to their inclusion in the group.

All interviews were individually conducted, each lasting 40-50 minutes.

\section{Participants}

The sample comprised nine participants, seven of them were women, who were caregivers of $\mathrm{PwD}$ [29]. The mean age of the participants was $(\mathrm{M}=52,33 \mathrm{SD}=12,45$ range $=34)$. The main criteria for the participants' recruitment were that, (a) all participants were caregivers of $\mathrm{PwD}$ in mild and moderate stages. This means that the average time between diagnosis and the participation to the study was 5 years $(\mathrm{M}=5,33 \mathrm{SD}=1,80$ range $=5)$; (b) all participants were receiving counseling support at the Caregivers' Center and had only recently started joining the support groups $(\mathrm{M}=1,55 \mathrm{SD}=0,52$ range=1). The names of the participants were confidential. Each of them has been given a code (P1-P9) in order to maintain confidentiality. The demographics of the sample are shown in Table 1.

\section{Interview}

The interview format was semi-structured. Questions were divided into three specific categories: "Initial feelings", "Feelings between receiving the diagnosis and starting psychotherapy" and "Beliefs and experiences from psychotherapy".

Specifically, in the first part, participants were asked to express their initial feelings at the time they were informed about the diagnosis, and tell about the first reactions and automatic thoughts. Afterwards, they were asked to talk about the emotional stages they had gone through, the specific time when they had started considering the need for help seeking, what motivated them to seek help and whether in certain occasions they had avoided help seeking despite their need.

In the second part of the interview, the questions focused on the period between the time of diagnosis and the beginning of psychotherapy. Specifically, if something had happened during that period, if there was something that delayed them from asking help, or if there was something that motivated them to ask for support.

The last part of the questions focused on their beliefs about psychotherapy, what expectations they had before they started it, and whether these expectations were confirmed or not. Finally, they were asked if they had been involved in any form of psychotherapeutic support before, how it affected them and what they expected for the future.

\section{Analysis}

All interviews were initially transcribed verbatim and analyzed. Following transcription, the first author analyzed each individual transcript using Interpretative Phenomenological Analysis (IPA). Each transcript was read carefully several times, and the tape recordings were heard, in order to ensure full emersion of the data, and capture all aspects of the participants' voices. In order to guarantee the coder reliability, the first author coded the individual scripts as to (1) the linguistic content (the specific characteristics of each participants' use of language e.g. which words use to refer to his/her relative who care for), (2) the content (what the participants were describing, what are they talking about) and, finally, (3) the conceptual understanding (interpretation of possible meanings) and tried to narrow down a list 
Table 1: Participant demographics.

\begin{tabular}{|c|c|c|c|c|c|c|c|c|c|}
\hline & P1 & P2 & P3 & P4 & P5 & P6 & P7 & P8 & P9 \\
\hline Gender & Female & Male & Female & Female & Female & Male & Female & Female & Female \\
\hline Age & 38 & 67 & 58 & 33 & 54 & 40 & 56 & 58 & 67 \\
\hline Marital status & $\begin{array}{c}\text { Not } \\
\text { Married }\end{array}$ & $\begin{array}{l}\text { Married } \\
\text { (1child) }\end{array}$ & $\begin{array}{c}\text { Married } \\
\text { (3children) }\end{array}$ & $\begin{array}{c}\text { Married } \\
\text { (2children) }\end{array}$ & $\begin{array}{c}\text { Married } \\
\text { (2children) }\end{array}$ & $\begin{array}{c}\text { Married } \\
\text { (2children) }\end{array}$ & $\begin{array}{l}\text { Divorced } \\
\text { (2children) }\end{array}$ & $\begin{array}{c}\text { Married } \\
\text { (2children) }\end{array}$ & $\begin{array}{c}\text { Not } \\
\text { Married }\end{array}$ \\
\hline Professional status & Freelance & Retired & Retired & Freelance & Retired & Freelance & Retired & Retired & Retired \\
\hline $\begin{array}{l}\text { Relationship with } \\
\text { patient }\end{array}$ & Father & Husband & Mother & Mother-In-Law & Father & Mother & Mother & Sister & Sister \\
\hline
\end{tabular}

of emergent themes based on the interpretation of each participant's answers to the questions, which were then placed into super-ordinate themes for each individual participant. This process was repeated for all transcripts. Then, the second author met with an external coder to discuss the final definitions of the themes and to reach an agreement on the coded units. Disagreements between the coders were resolved through discussion. Following this approach, the coders agreed up to $100 \%$ on the final identification of the themes and then the first coder finalized the "significant statements" that clarified each of the themes.

\section{Results}

The results are organized in three sections following the three parts of the interview. The categories of responses are shown along with representative examples taken from the interviews.

\section{Experiencing the diagnosis}

The following categories describing caregivers' experience at the time of the diagnosis.

The diagnosis as confirmation: Most descriptions of the experience upon receiving the diagnosis used the word "confirmation", but for each participant had a different meaning.

P1: I understood exactly what was happening all these years. I didn't take it to the heart. On the contrary, I felt a sense of justice for Dad because of the reactions he had, which others did not understand. At the end, he was not to blame, he was not a crooked man, a bad man or changed and everything was just a cause of illness. I felt he was justified.

This participant, besides feeling a confirmation of what she had suspected long ago, felt justified about her negative emotions towards her father, as she was relieved that he was not a 'bad' man at all, but the illness made him behave in this way.

P3: Yes, I expected it, I wasn't shocked ... I didn't feel anything special ... It didn't impress me, it's something I expected.

P3, discusses the moment of the diagnosis when she went with her mom to the doctor. The diagnosis confirmed what P3 already expected. This confirmation, however, was not associated with any other emotions.

P7: It didn't make any impression on me. I thought, yes, I got it right, and I got it right anyway. And I wish I had the awareness for myself to understand that something is happening to me to act as soon as possible.

P7, with a cold expression on her face, stresses that she understood it from the beginning and she was satisfied from her reaction to the symptoms of the disease.
The diagnosis as a loss: The term 'loss' was often mentioned in the interviews to express the participants' feelings both at the time of diagnosis and during the progress of the disease. This category belongs to the first part of the interviews describing the first feelings and changes in their lives. It referred to the loss of parental protection, loss of help from one's parents or from one's companion.

P5: It is too difficult...Look, the feeling is very strange; I have been away from home since I was 18 . But in reality, no ... To say that my dad is here, it helps me,... to say that I'm in the family home, as others do, to say that my parents helped me raise my kids, cooked for me, I didn't have those things and yet the feeling comes that now yes, you are alone.

P5, feels strongly that she is now losing her father, her father in the role of protector.

P8: Now it bothers me ... she is like a kid... not always, but she argues with my granddaughter... Of course, you can say that she is not very well. I can understand it, but when you are in a house with so many people, it is not easy to say that... what I can say (?)

P8: I cannot recognize myself. I was another person, calm, relaxed...I was a positive person, calm, always I recognized the positive side of life... I try again to think positive.... I can no longer bear to justify as I did and succeed.

P8, presents both sides of the disease. The loss of main characteristics of the patient's character, but also a change in some characteristics of the caregiver, because of the unknown situation or the loss that she experiences.

The diagnosis and feelings of helplessness: Many participants experienced the diagnosis of dementia as a sense of helplessness, as a situation that their loved ones are weak now.

P8, talked about her fear for the future. The main thought she mentioned that she keeps having about the progression of the disease is "weakness" and it changes the main personality characteristics. In addition, most of the participants referred to their 'inability' to manage the situation, both physically and emotionally, and deal with the new situation arising after the diagnosis. Also, they mentioned their concern about whether they would have the ability to deal with the symptoms of the disease or, even, concern whether something bad would happen to their own health.

Characteristically, P1 said with a loud voice that she feels unable to help her dad, she doesn't know what to do.

P1: You feel sad when he doesn't feel well ... I have seen myself many times reacting wrongly, nervously or abruptly because essentially, I feel that I cannot help him... And this has as a result to 
feel discomfort. My dad can understand my feelings, and everything is getting worse.

P8, on the other hand, feels that the burden of her sister's condition is so heavy that she cannot stand it anymore. Thus, she comes face to face with a harsh awareness of her own sense of helplessness.

P8: My personality has always been relaxed, I have not been disturbed by anyone... I do not let people to exploit me because I'm a calm person. I try to be powerful, but in this situation, I feel that I have been broken.

The diagnosis as a responsibility: Most caregivers mentioned the huge responsibility they feel after receiving patient's diagnosis. Many times, this responsibility was like a 'challenge' or 'bet'. They assume this responsibility not only as a burden, but also as an opportunity to assess their capabilities.

P2: I felt guilty. I felt bad that I couldn't help her enough. ... I was sad ... of course, because I felt responsible towards my family about this matter.

P2: I feel that the purpose of this life is to give as much as possible to other people... I need to give, not to receive.... I do not feel it is a debt, but a sense of responsibility. I feel responsible, I have been with her for 40 years, and I am obliged until I close my eyes to take care of her.

The diagnosis as a trauma: For some participants the diagnosis looked like a trauma. In other words, as a shock that stigmatized them. On the other hand, for others, it was a springboard to open up the already existing 'trauma' to their relationship and to arise the existing and unconscious entanglements.

P5: It was very hard for me to believe it. I said I don't want to think about it. I think, of course, that it's been 30 years since I left from my dad's home, but dad was always the stronger in the family. That's why my 'world' was destroyed with the announcement of the diagnosis... Yes, yes it was scary.... No, I didn't want to accept it. I never told that to my brother, because I denied this information and I did not believe it.

\section{The post-diagnosis experiences}

This is the second issue that was included in the participants interviews. It was about their experience with the disease, after the announcement of the diagnosis until the beginning of psychotherapy.

Developing defenses: An important issue that emerged from the caregivers' description of their experience with the disease was the development of defenses. Specifically, one of the most important defenses reported was "ignorance", that is, not knowing exactly what the disease is, possibly as a means of protection against negative emotions.

For example, P1 started psychotherapy some months after diagnosis. As said, at the beginning, she didn't know much about the disease, that's why she did not have strong feelings during the diagnosis. As she started to learn more, this situation was changed.

P1: Dementia is a field that we don't really know... When, finally, I started to understand exactly what dementia is through the behaviors of my Dad, then strong feelings came up to the surface.
Also, "idealization" was another defense identified in participants interviews. That is, many participants exaggerated the positive qualities of their loved ones. P1, for example, referred to her Dad talking with an overly positive way, even though she had said that she did not have a good relationship with him in the past ...

Loneliness: Feelings of loneliness were mentioned by some participants to occur in the period after the diagnosis and during their caring role.

P5: In the announcement of dad's diagnosis, although she had worked on the relationship with her father with a psychotherapist, she said that she suspected this idea of dementia completely, because she felt that she will be totally alone.

P5: But yes there was the feeling that now you are alone ... It is a feeling, that you are alone, my dad will can't take any decision anymore, you will be alone, and you will not have anyone to help you. I felt like a little child ... Although I have taken all the responsibilities of myself from the age of 18 .

In addition, in the question about the delay in asking for help from a support group, many participants referred to the complexity of situations they were facing for which they had to deal without any support and external contextual issues (e.g., a lot of pressure at their work and their family environment).

P8, as well as P6 and P4, said that they had to deal with other difficult situations, they didn't have any assistant from anyone and that is why they delayed seeking support.

P8: Things were happening all together! My daughter came home and that created a lot of problems... Could I think of myself? We had to deal with all these issues, and when, finally, we started to have a balance, I said now I can think of myself. Previously, I had no time for thoughts.

Finally, it is crucial to note also a sense of "omnipotence", as an over-reaction related to the responsibility of the caregiver that also created feelings of loneliness. For example, P2 repeated that many times he tried alone to do the best to keep his wife in this stage of dementia or to go back to a previous stage.

P2: I just wanted to get back to a previous stage. I tried to help her to be as she was 3-4 years ago. I said I would try to keep her either on the same stage or to make any improvements through my caring role. That was all my thoughts.

For example,

P5: But yes, there was the feeling that now you are alone ... my dad will not be able to make any decision anymore, you will not have anyone to help you. I felt like a little child.

P3, in this crucial condition with her mom she visited a psychiatrist, but she stated that she could not articulate anything after the diagnosis...

P3: We didn't have many sessions.... Now I want to ask him to have some. All that I have told you now, I have not told him... We met him a few times, just for a pharmacological therapy and I did not talk about anything.... I don't know, apparently, he didn't ask me and it was difficult for me to share deeper feelings. Maybe my physical 
health was in the first line.

Reaching the limits: Most participants mentioned that they had faced a 'crisis' situation after the diagnosis announcement up to the time they decided to seek help. The common feeling in all cases was anger towards the diagnosis and, also, for all the difficulties they were facing at that time. This was also the main motivation for seeking support.

For example, in P8's description, it looks like she had reached her limits and then she decided to seek help.

P8: I felt that I would kill somebody... I tried to think positive. I excuse all people for everything... I could no longer do it.

\section{Understanding psychotherapy}

The last issue in the interview regarded the participants' initial perception of psychotherapy and how it influenced them in help seeking. Also, the perceived benefits from getting help in the support group they were attending up to that point and the perceived prospect of their participation in support groups. Finally, the need for 'deeper' personal openness apart from the difficulties caused by the disease was brought up.

Need and relief: Many participants reported an urgent need for help seeking. Their initial perception of psychotherapy and the expectation from it was that they would feel relief and support. They also realized the importance of sharing their experiences with others.

Specifically, P2 referred to psychotherapy as a need for help. The help would support the management of the patient as well as of themselves.

P2: I felt the need for help, to get some advice to handle this whole situation in a better way. Not to harm myself and my spouse.

P1, mentioned the need for sympathy and someone to understand her feelings. Also, the need to share her feelings with other people with similar experiences. When she was informed about this kind of support group, she was relieved and grateful.

P1: I was relieved and glad, because I felt that it was a necessity. I had wished to find it, and indeed once I learned that there is a kind of help, I felt grateful.

Empowerment and alliance: Some participants believed that psychotherapy would empower them, would be an alliance that would help them deal with their difficulties. Also, it would be an appropriate way to get advice and useful tools to manage their life. This kind of support was expected to satisfy their need to enhance their well-being and coping with difficulties in the future.

Specifically, P1 mentioned that she had found exactly what she had wished to find, and she hoped to keep participating in the support group in order get some practical tips, be calm and start taking better care of herself.

P1: Practical tips and ways to cultivate my calmness, to help me deal with difficulties... Yes, firstly for myself, because my dad's feelings depend on my feelings.

Opportunity to "open up" as a person: At the end of the interview, most participants reflected on their experiences in the support group.
They mentioned examples of a different way of thinking about their own feelings and behavior, and the reasons that might underlie them. This was associated with a need to start individual psychotherapeutic sessions in order to go deeper into their thoughts and feelings, go beyond the disease and try for an 'opening up' to their inner self.

$\mathrm{P} 1$, very characteristically stated that she perceived psychotherapy as an occasion for sympathy and unconditional acceptance and she referred to her need for individual psychotherapy.

P1: In the support groups, I can express everything I feel, with people that I know they will listen to me carefully.

\section{Discussion}

The present study focused on how caregivers experience the diagnosis of dementia and the disease. It provided an in-depth analysis of caregivers' interviews on their emotions and their change until psychotherapy in support groups had started.

With regards the diagnosis, the analysis of the interviews showed that many participants experienced the diagnosis as a confirmation what they already had suspected. It is worth noting that after the diagnosis announcement, many $\mathrm{PwD}$ and their caregivers were relieved from the stress of uncertainty and ambiguity. This finding is in line with those of previous research $[25,26,30,31]$. Pepersack (2008) [32] also states that the communication of diagnosis has a positive impact to patients' feelings and, also, to the whole family, because before the announcement of diagnosis, they all suffered from the stress of dealing with an uncertain situation. At first, they did not notice the symptoms, whereas secondly, they did notice but ignored them. When symptoms became more evident, the diagnostic process and the revelation followed, accompanied by feelings of confirmation or shock, denial or judgment, disorganization or adjustment. During the interviews, everyone mentioned their personal difficulty in accepting the diagnosis, and each one of them, in a different way, associated it with loss, which also appears in a large number of studies $[8,33,34]$.

In the experiences of our study's participants, we encountered reports and feelings similar to the path of accepting a loss. This transition, according to Kubler-Ross (1973) [33], follows the stages of denial, anger, negotiation, depression, and acceptance, whereas according to Bowlby $(1998,2008)$ [34,35], the stages of accepting a loss are the sense of shock, the search for an interpretation, the intense sadness and the reorganization of life. The same findings emerged in a similar study by Czekanski (2017) [36]. Changing roles and differences in relationships were more likely to capture the sense of loss.

Additionally, according to the extensive references found in literature [7,37-41], caregivers have feelings of loneliness, isolation, boredom, and frustration. In this case, as Koca et al. (2017) [42] reported, the despair, fatigue, and loneliness experienced by caregivers significantly increased the overall burden of the disease. Moreover, aggravating feelings, which were stressed by the participants, were the sense of commitment, lack of time for themselves and lack of rest, even for a short time period. This leads them to restrict their social life around the obligations of care [43,44]. In addition, as separated from the thematic of the present study, many caregivers entered the 
psychotherapeutic groups the post-diagnosis period, in a period of silence in which they were not sharing their experiences.

- $\quad$ Based on the statements of most participants, the diagnosis announcement raised strong issues of responsibilities. Many caregivers are overwhelmed by these responsibilities as well as the feeling of being unable to cope with this situation 45,46 . Additionally, it was further observed that caregivers were shocked when hearing the diagnosis, stating that for them this experience was a trauma. Numerous studies have reported that caregivers report posttraumatic stress disorder both in patients diagnosed with a chronic illness as well as their relatives $[6,47,48]$.

- Additionally, one of the most important sub-topics that emerged from this research was the development of defenses adopted by caregivers. In the present study caregivers' defenses emerged during the period from diagnosis to support seeking. This is essentially a factor that affects the caregivers' burden, as it determines when they will eventually seek help. The defense mechanisms which were revealed through our study, in addition to the protection they provided to the participants, delayed them from seeking support and adopt coping strategies.

- $\quad$ One of the subsections of our "Post diagnosis experience" theme was to manage the crisis situations under which participants came through before deciding to start psychotherapy. In the phenomenological study by Aminzadeh et al. (2007) [49], the emotional crisis of caregivers associated with the experience of actual or expected loss was also revealed as a main theme of their study.

As the phenomenological study by Pepersack (2008) [32] pointed out, caregivers have a great need to seek knowledge and information about the disease. In addition, the need for support was of outmost importance. As it has been described by many caregivers, seeking knowledge and support can be assumed as a way to get out of the difficulties and deal with the symptoms of the disease [50]. In our study also, all participants mentioned that they wanted to have some form of support as a kind of necessity. Everyone mentioned that, through their participation in the psychotherapy group, have found relief through sharing their feelings and realizing that they are not alone.

\section{Conclusions}

Caring for a PwD is complex, as is the journey during bereavement. This study presents prominent emotions and experiences discussed by nine caregivers of PwD from the time of diagnosis to their current stage of taking part in support groups. The study suggests that confirmation, sense of loss and helplessness, the responsibility for care and the trauma feelings are the most pronounced emotions felt during the announcement of diagnosis, while anger and the sense of loneliness are experienced through the post diagnostic period. Despite that caregivers delay to seek help, group support experience is an important source for relief, empowerment, and openness.

This study highlights that psychologists and psychotherapists, who implement support interventions for caregivers, can take into account the feelings reported from the caregivers of this study, as well as their experiences at the time of the diagnosis. They can also create new kind of interventions that will include methods aiming to improving this first experience of diagnosis.

\section{Limitations}

For this study, a small group of participants of a limited age group (33-67 years) and geographical area (Thessaloniki) was used. Given the above limitation, and the fact that all participants come from the same support framework -DCCSH- it should not be concluded that the results will be the same for all caregivers. Each qualitative study, which is based on interviews and their interpretations by one or more researchers, is exploratory and difficult to replicate leading to a broader conclusion [51].

Furthermore, there were differences between the participants' statements, which may have been influenced by their experiences, such as whether they had previously had a personal experience in psychotherapy and the type of affinity they had with the patient.

Finally, another important limitation of the study is the gender, because the majority of participants were women with the exception of two men. While this may be due to the higher percentage of women in the caregiver position, men's narratives in this role may vary. Although the findings of this study are valid for this population sample, it cannot be confirmed that all caregivers face, or have undergone, the same experiences regarding the first feelings at diagnosis. However, the similar use of language used by participants to describe their feelings or experiences as a whole, identifies a core of common themes, which could indicate how strongly they were influenced by the topic under consideration, and therefore, this study could be used as an example for further research [52].

\section{Disclosure Statement}

The author(s) declared no potential conflicts of interest with respect to the research, authorship, and/or publication of this article.

\section{References}

1. Alzheimer's Disease International. Dementia statistics. 2018.

2. Alzheimer's Association website. Alzheimer's disease facts and figures. 2018.

3. Grabher BJ. Effects of Alzheimer Disease on Patients and Their Family. Journal of Nuclear Medicine Technology. 2018; 46: 335-340.

4. Landeiro F, Wace H, Ghinai I, Nye E, Mughal S, Walsh K, et al. Resource utilization and costs in predementia and dementia: a systematic review protocol. Geriatric medicine. 2018; 8: e019060.

5. Das R. A silver tsunami invades the health of nations. 2015.

6. Elklit A, Blum A. Psychological adjustment one year after the diagnosis of breast cancer: A prototype study of delayed post-traumatic stress disorder. British Journal of Clinical Psychology. 2011; 50: 350-363.

7. Greenwood N, Pound C, Brearley S, Smith R. A qualitative study of older informal cargivers' experiences and perceptions of their caring role. Maturitas. 2019; $124: 1-7$.

8. Holley C K, Mast B T. The impact of anticipatory grief on caregiver burden in dementia Caregivers. The Gerontologist. 2009; 49: 388-396.

9. Kilty C, Boland P, Goodwin J, de Roiste A. Caring for People with Young Onset Dementia. An Interpretative Phenomenological Analysis of Family Caregivers' Experiences. Journal of Psychosocial Nursing and Mental Health Services. 2019; 57: 37-44.

10. Liew TM, Tai BC, Yap P, Choon-Huat Koh G. Development and validation of a simple screening tool for caregiver grief in dementia caregiving. BMC Geriatrics. 2019; 19: 54. 
11. Sörensen S, Pinquart M, Duberstein P. How effective are interventions with caregivers? An updated meta-analysis. The Gerontologist. 2002; 42: 356 372.

12. Van der Lee J, Bakker THEM, Duivenvoorden HJ, Dröes RM. Do determinants of burden and emotional distress in dementia caregivers change over time? Aging \& Mental Health. 2017; 21: 232-240

13. Van der Lee J, Bakker TJEM, Duivenvoorden HJ, Dröes RM. Multivariate models of subjective caregiver burden in dementia: A systematic review. Ageing Research Reviews. 2014; 15: 76-93.

14. Alzheimer's Disease International. World Alzheimer Report 2011: The Benefits of Early Diagnosis and Intervention. London: ADI. 2011.

15. Fitzgerald JA, Curry J, OldeMeierink A, Cully A. Putting the consumer in the driver's seat: A visual journey through the Australian health-care system as experienced by people living with dementia and their cargivers. Australasian Journal on Ageing. 2019; 38: 46-52

16. Phillips J, Pond D, Goode S. Timely diagnosis of dementia: can we do better. A report for Alzheimer's Australia. Canberra: Alzheimer's Australia. 2011.

17. Brooker D, Fontaine JL, Evans S, Bray J, Saad K. Public health guidance to facilitate timely diagnosis of dementia: Alzheimer's Cooperative valuation in Europe recommendations. International journal of geriatric psychiatry. 2014; 29: 682-693.

18. Vernooij-Dassen M, Moniz-Cook ED, Woods RT, De Lepeleire J, Leuschne $\mathrm{A}$, Zanetti $\mathrm{O}$, et al. Factors affecting timely recognition and diagnosis of dementia across Europe: from awareness to stigma. International Journal of Geriatric Psychiatry. 2005; 20: 377-386.

19. Iliffe S, Manthorpe J, Eden A. Sooner or later? Issues in the early diagnosis of dementia in general practice: a qualitative study. Family Practice. 2003; 20: $376-381$

20. Karagiozi K, Margaritidou P, Egkiazarova M, Toumpalidou M, Makri M, Tsolaki M. Interventions for Caregivers of People with Dementia in Greece. Journal of Family Medicine. 2017; 4: 1125

21. Etters L, Goodall D, Harrison BE. Caregiver burden among dementia patient caregivers: a review of the literature. Journal of the American Academy of Nurse Practitioners. 2008; 20: 423-428.

22. Pendergrass A, Becker C, Hautzinger M, Pfeiffer $K$. Dementia caregive interventions: a systematic review of caregiver outcomes and instruments in randomized controlled trials. International Journal of Emergency Mental Health and Human Resilience. 2015; 17: 459-468.

23. Karagiozi K, Papaliagkas V, Giaglis G, Papastavrou E, Pattakou E, Tsolak M. Combined Intervention for Caregivers of Patients with Dementia: A Randomized Controlled Trial. International Journal of Academic Research in Psychology. 2014; 1: 77-95.

24. Robinson L, Clare L. Evans K. Making sense of Dementia and adjusting to loss: Psychological reactions to a diagnosis of dementia in couples. Aging and Mental Health. 2005; 9: 337-347.

25. Swallow J, Hillman A. Fear and anxiety: Affects, emotions and care practices in the memory clinic. Social Studies of Science. 2019; 49: 227-244.

26. Tuffrey WI. Breaking bad news tool. 2012

27. Hefferon K, Gil-Rodriguez E. Interpretative phenomenological analysis. The Psychologist. 2011; 24: 756-759.

28. Smith JA, Shinebourne P. Interpretative phenomenological analysis. In H. Cooper P M, Camic DL, Long AT, Panter D, Rindskopf KJ, Sher (Ed), APA handbooks in psychology. APA handbook of research methods in psychology. Research designs: Quantitative, qualitative, neuropsychological, and biological. American Psychological Association. 2012; 2: 73-82.

29. Reid K, Flowers P, Larkin M. Exploring lived experience. The Psychologist 2005; 18: 20-23

30. Szymczynska P, Imes A, Marson A, Stark C. A review of diagnostic process and post diagnostic support for people with dementia in rural areas. Journa of primary Care \& Community Health. 2011; 2: 262-276.

31. Whitehouse P, Frisoni BG, Post S. Breaking the diagnosis of dementia.
Lancet Neurol. 2004; 3: 124-128.

32. Pepersack T. Disclosing a diagnosis of Alzheimer's disease. Article in French Revue Médicalede Bruxelles. 2008; 29: 89-93.

33. Kubler-Ross E. On Death and Dying. New York: MacMillan Publishing. 1969.

34. Meuser TM, Marwit SJ. A comprehensive, stage-sensitive model of grief in dementia caregiving. The Gerontologist. 2001; 41: 658-670.

35. Bowlby J. A secure base. New York: Basic Books. 1998.

36. Bowlby J. Attachment and loss: Loss, sadness and depression (3). New York: Basic Books. 1980.

37. Czekanski K. CE: Original Research: The Experience of Transitioning to a Caregiving Role for a Family Member with Alzheimer's Disease or Related Dementia. American Journal of Nursing. 2017; 117: 24-32.

38. Caregivers UK. Alone and Caring: Isolation, Loneliness and the Impact of Caring on Relationships. London. 2015.

39. Cutrino A, Santamaria J. Research on family caregivers: understanding levels of burden and how to provide assistance. Home Healthcare Nurse. 2013; 31: 331-337.

40. Daly L, McCarron M, Higgins A, McCallion P. "Sustaining Place" - A grounded theory of how informal cargivers of people with dementia manage alterations to relationships within their social worlds. Journal of Clinical Nursing. 2013; 22: $501-512$.

41. Rajna P. Living with lost individuality. Special concerns in medical care of severely demented Alzheimer patients. IdeggyogySz. 2010; 63: 364-376.

42. Vasileiou K, Barnett J, Barreto M, Vines J, Atkinson M, Lawson S, et al. Experiences of loneliness associated with being an informal caregiver: a qualitative investigation. Frontiers in Psychology. 2017; 19: 585.

43. Koca E, Tskapilioglou O, Bakar M. Caregiver Burden in Different Stages of Alzheimer's Disease. NoroPsikiyatrArs. 2017; 54: 82-86.

44. Purola R. Experiences of home-dwelling stroke patients and their relatives about coping. Academic Centre for Dentistry Amsterdam. University Oulu Nisi, Series Medica D 577. Oulu University Press, Oulu. 2000.

45. Pyykko R, Hentinen M, Backman K. Experiences of home care situations and some ways to cope with them as reported by spouses of persons with dementia. Hoitotiede. 2001; 13: 266-276.

46. Mayo A, Siegle K, Savell E, Bullock B, Preston G, Peavy G. The Lived Experience of Lay Caregivers Caring for Persons with Dementia. American Academy of Neurology. 2019; 92.

47. Ornstein KA, Gaugler JE. Devanand DP, Scarmeas N, Zhu CW, Stern Y. Are there sensitive time periods for dementia caregivers? The occurrence of behavioral and psychological symptoms in the early stages of dementia. International Psychogeriatrics. 2013; 25: 1453-1462.

48. Lemaistre JA. After the diagnosis: From crisis to personal renewal for patients with chronic illness. Ulysses Press. 1995

49. Van den Born-van, Zanten SA, Dongelmans DA, Dettling-Ihnenfeldt D, Vink $\mathrm{R}$, Van der Schaaf M. Caregiver strain and posttraumatic stress symptoms of informal caregivers of intensive care unit survivors. Rehabilitation Psychology. 2016; 61: 173-178

50. Aminzadeh F, Byszewski A, Molnar FJ, Eisner M. Emotional impact of dementia diagnosis: Exploring persons with dementia and caregivers' perspectives. Aging \& Mental Health. 2007; 11: 281-290.

51. Dovi E, Bier JC, Fantini-Hauwel C. Dementia caregiver journey and motivation to participate in a psycho-educational group: an interpretative phenomenological analysis. Geriatric Psychologyand Neuropsychiatry Vieil. 2019; 17: 439-447.

52. Willig C. Introducing qualitative research in psychology. McGraw-Hil International. Open University press. England. 2013.

53. Banister P, Bunn G, Burman E, Daniels J, Duckett P, Goodley D, et al Qualitative Methods in Psychology: a research guide (3). Berkshire (OU) \& New York (McGHE): Open University Press. 2012. 